\title{
Strengthening capacity to prevent HIV among adolescent girls and young women: Supporting DREAMS programming
}

Project SOAR

Follow this and additional works at: https://knowledgecommons.popcouncil.org/departments_sbsr-hiv

Part of the Demography, Population, and Ecology Commons, Family, Life Course, and Society Commons, International Public Health Commons, and the Women's Health Commons How does access to this work benefit you? Let us know!

\section{Recommended Citation}

Project SOAR. 2019. "Strengthening capacity to prevent HIV among adolescent girls and young women: Supporting DREAMS programming," Project SOAR Results Brief. Washington, DC: Population Council. 


\section{Strengthening Capacity to Prevent HIV among Adolescent Girls and Young Women: Supporting DREAMS programming}

\section{Inspiring a new way of thinking}

Adolescent girls and young women (AGYW) in low- and middle-income countries often are disadvantaged by discriminatory gender norms and practices-which can undermine their access to opportunities, services, and resources. Despite decades of investment in HIV prevention, many AGYW remain invisible, underserved, and at disproportionate risk of HIV.

\section{It's clear we need to think more about reaching the right girls." \\ -Center for Disease Control representative, Haiti}

The DREAMS (Determined, Resilient, Empowered, AIDS-free, Mentored, and Safe) Partnership ${ }^{1}$ aims to significantly reduce HIV infections among AGYW. DREAMS is groundbreaking in its commitment to deliver evidence-informed approaches that go beyond the health sector to address structural factors that fuel AGYW's HIV risk, including poverty, gender inequality, sexual violence, social isolation, and lack of schooling.

DREAMS originally launched in 2014 , focusing on 10 high-burden countries in sub-Saharan Africa. The Population Council, with funding from Girl Effect, worked in seven ${ }^{2}$ DREAMS countries to strengthen the capacity of implementing partners (IPs) to develop new approaches to reach AGYW at highest risk of HIV infection, link them with essential resources, and empower them with social and protective assets for a safe and healthy entry into adulthood. This technical assistance was informed by the Population Council's decades of research and experience determining 'what works'-and what doesn't work-in girl-centered programming.

${ }^{1}$ DREAMS is supported by the US President's Emergency Plan for AIDS Relief (PEPFAR), the Bill \& Melinda Gates Foundation, Girl Effect, Johnson \& Johnson, Gilead Sciences, and ViiV Healthcare.

${ }^{2}$ Kenya, Malawi, Mozambique (supported through Project SOAR), South Africa, Tanzania, Uganda, and Zambia.

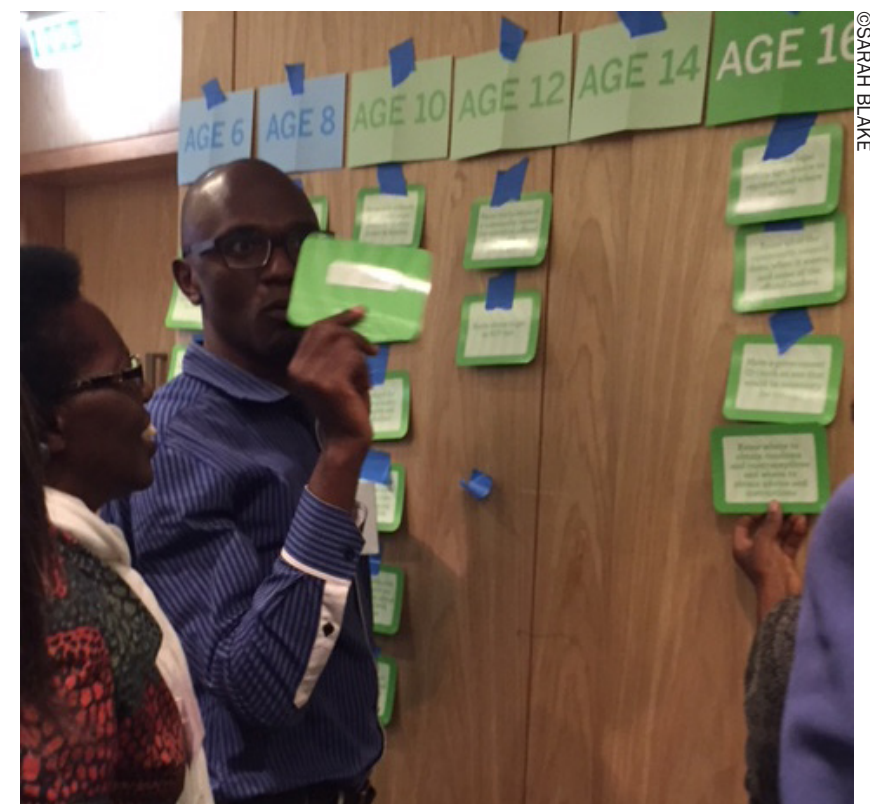

Participants at a workshop in Rwanda use the Population Council's Building Assets Exercise to identify which protective assets AGYW need at different ages.

In 2017, DREAMS expanded support to five additional countries: Botswana, Cote d'Ivoire, Haiti, Namibia, and Rwanda. Through Project SOAR, the Council provided technical assistance (TA) to IPS in these countries to design and implement girlcentered programming based on evidence-informed concepts, tools, and tactics. The aim was to enable

\footnotetext{
The [Population Council's] Asset

Exercise was really practical, and it changed my way of seeing what adolescent girls and young women really need and when they need it."
}

-Ministry of Health representative, Namibia

IPs to use these approaches to improve their program coverage and delivery by reaching groups targeted by DREAMS: the most at-risk, marginalized AGYW, who are often-inadvertently-overlooked by conventional HIV prevention efforts. 


\section{OUR APPROACH}

We hosted five country-level "Evidence into Action" workshops, with a total of 150 participants representing 39 IPs, PEPFAR country teams, and government counterparts. Each workshop was tailored to the country's needs. Content included:

- Orientation to girl-centered concepts (Box 1) and tools, such as the Girl Roster ${ }^{\mathrm{TM}}$ (Box 2), that anchor AGYW at the center of program design, planning, and implementation with an emphasis on hard-toreach AGYW.

- Programmatic case studies (Box 3) to illustrate how workshop concepts and skills could be applied in the field.

\section{BOX 1 Girl-centered Concepts}

- Elite capture: A form of exclusion, where girls with the lowest risks receive most of the program benefits because they are easier to enroll in programs.

- Segmentation: Identifying the different subpopulations of AGYW (e.g., married AGYW, out-of-school AGYW, pregnant AGYW) in a catchment area to ensure programs are tailored to meet the specific risks and needs of their beneficiaries, using tools such as the Girl Roster ${ }^{\text {TM }}$ (Box 2).

- Walkable community: The resources and structures that AGYW can access while remaining healthy and safe. The walkable community is also defined by the people and resources that make up AGYW's social space, such as parents who may control their daughters' movements.

- Social and other protective assets: Tangible or intangible assets that empower AGYW and enable them to reduce their risks and expand their opportunities. Examples include identity cards, self-efficacy around condom use, and literacy and numeracy skills.

- Community-based platforms: Accessible, private, and safe spaces where AGYW, especially those who are socially isolated, can meet regularly with peers and mentors, and a range of interventions can be delivered.

\section{BOX 2 The Girl Roster ${ }^{\mathrm{TM}}$}

The Girl Roster ${ }^{\mathrm{TM}}$ is a brief questionnaire using non-sensitive questions administered via Android phones in 7-10 minutes. ${ }^{3}$ The tool collects information on age and martial, childbearing, schooling, and living-arrangement status of AGYW and generates real-time output tables, segmenting the collected information into AGYW sub-populations with different risk profiles. For example, the tool can identify and map "offtrack" AGYW-those who face the highest risks because they are out-of-school, married, have children, and/or do not live with both parentswhich in turn can improve outreach to and inclusion of this population in programs.

- Participatory activities, such as community mapping (Box 4), that put concepts to practice and helped reframe how participants viewed communities where they were implementing DREAMS activities.

- Strategies to recruit, train, and retain mentors-a vital resource in community-based AGYW programming.

- Individualized coaching sessions to develop actionoriented workplans on topics such as developing participant eligibility criteria and recruitment plans, mapping and identification of resources, and supporting and retaining mentors.

\section{LESSONS LEARNED}

Our capacity strengthening strategy focused on generating insights, challenging assumptions, and enabling IPs to innovate in their DREAMS implementation to reach AGYW who were often overlooked. As a result, we learned the following lessons:

\footnotetext{
${ }^{3}$ The Girl Roster ${ }^{\mathrm{TM}}$ was developed by the Population Council, Women's Refugee Commission, and operating organizations of the Girls in Emergencies Colaborative and is available for free to programmers, implementers, and governmental agencies. For additional information on the Girl Roster ${ }^{\mathrm{TM}}$ tool, please visit popcouncil.org/research/girl-roster or https://www.popcouncil.org/uploads/pdfs/2016PGY_ GirlsProtectiveAssetsTools.pdf. Detailed inquiries can also be sent to girlroster@popcouncil.org.
} 


\section{BOX 3 Case Study-The "Right" AGYW in DREAMS}

In Botswana, Namibia, and Rwanda, workshop participants learned how Global Communities, a DREAMS IP in Kenya, used information from the Girl Roster ${ }^{\mathrm{TM}}$ to adjust its eligibility criteria to include 'invisible girls,' such domestic workers, migrants, and Somali/Oromo girls from the Muslim community. As the latter population face specific language barriers to participation, the program also recruited Somali/Oromo-speaking mentors to facilitate inclusion of these girls. Implementation of the Girl Roster ${ }^{\mathrm{TM}}$ tool had the additional benefit of raising the profile of DREAMS in the community, in turn enhancing acceptability of the program.

- Tailoring content to the expressed needs of each country enabled the translation of learnings into programmatic action. Facilitators who can disseminate information and train in the local language, with knowledge of the context, is essential.

- Having the right people in the room helped make a successful workshop. With each invitation, organizers clearly specified who (e.g., monitoring and evaluation personnel, chief of party, middle managers) should attend each day. We advised that multiple people with various backgrounds from each organization participate to facilitate information sharing with colleagues back at the office.
- IPs benefited from the opportunity to collaborate and coordinate with one another; some continued to meet regularly after the workshops to discuss implementation challenges and lessons learned. Supporting this collaboration after the workshop is a way to optimize its impact.

- Community mapping was an effective approach to gauge participants' knowledge of their program communities and verify or refute underlying assumptions about resources, residents, risky features, and locations of AGYW.

\section{I have been walking around the community for two years now, and when we did the community resource mapping yesterday-it changed my life. Walking through the community center [and] looking at it from the perspective of a 15- to 17-year- old girl made me realize that the community might be a hazard and the girl might not feel safe. I always take my car to the mechanic for a car wash; until yesterday, it has been a really nice community center-but the walk made me realize that what I see as resources, can be hazards to a young girl" \\ -Orphans and Vulnerable Children Coordinator Government of Botswana}

- There is a high demand for local, real-time AGYW information that can be used to inform program design and delivery.

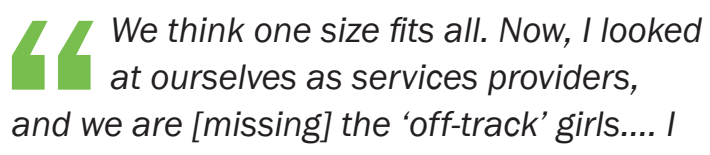

\section{BOX 4 Community Mapping: Programming guided by the girl's perspective}

In Botswana, workshop participants undertook a community mapping field exercise. Walking through the neighborhood of Gaborone West, small groups scanned the community through the lens of a girl "segment" (e.g., a 15-year-old who is married with two children and does not go to school nor live with her parents), identifying potential resources, hazards, safety points, and community-based platforms.

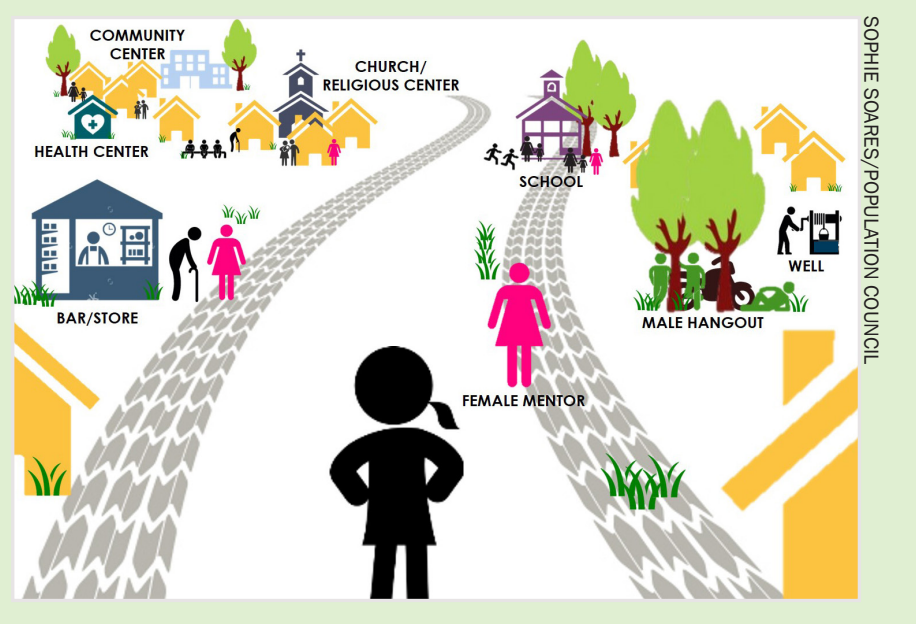


talked to the M\&E [monitoring and evaluation] person back at the office and asked him to do something about it.

-IP Chief of Party, Namibia

\section{- Participants expressed the need for additional support and assistance, for example, to create mentor guides and to implement and interpret information from the Girl Roster ${ }^{\mathrm{TM}}$ tool.}

\section{IMPACT}

Through interactive workshops and tailored followup TA, we were able to reshape the way many IPS viewed, approached, and understood programming and the communities in which they work:

- Participants demonstrated increased knowledge of girl-centered programming, social and physical factors that inhibit girls' access to services and resources, and essential characteristics of mentors and community-based platforms (also known as "safe spaces").

- In Cote d'Ivoire and Rwanda, participants rostered 6,603 households in 17 communities-ultimately collecting information on 8,357 AGYW. They used this information to help shape program activities and services, inform recruitment and enrollment efforts, and/or to lay the groundwork to assess program coverage. Table 1 shows the information collected in one community in Cote d'Ivoire.

- Viewing communities from an AGYW's perspective helped programs make groups and services more accessible.

- As an essential component of community-based AGYW programming, mentors are the main deliverers of core content and serve as bridges to services; however, they cannot and should not do everything. To ensure this, we advised IPs to establish a mentor support framework-including competitive compensation, proper supervision, and constructive feedback-in order to recruit, train, and retain high-quality mentors.

- Following each workshop, a team of experienced coaches provided TA to select IPs, including those that could disseminate information to other IPs incountry, laying the groundwork for a sub-national community of practice. Follow-up TA included technical backstopping for the Girl Roster ${ }^{\mathrm{TM}}$ tool including the best use of rostering outputs, webinars on specific programmatic topics, remote coaching sessions, in-country "office hours," and assisting with key program documents.

Suggested citation: Project SOAR. 2019. "Strengthening capacity to prevent HIV among adolescent girls and young women: supporting DREAMS programming," Project SOAR Results Brief. Washington, DC: Population Council.

Table 1 Girl Roster information for a community in Cote d'Ivoire

\begin{tabular}{|c|c|c|c|c|c|c|c|c|c|c|}
\hline & \multicolumn{7}{|c|}{ Unmarried } & \multicolumn{2}{|c|}{ Married } & \multirow[t]{3}{*}{ Total } \\
\hline & \multicolumn{3}{|c|}{ In-school, no children } & \multicolumn{3}{|c|}{ Out-of-school, no children } & \multirow{2}{*}{$\begin{array}{l}\text { Has a } \\
\text { child }\end{array}$} & \multirow{2}{*}{$\begin{array}{l}\text { Has a } \\
\text { child }\end{array}$} & \multirow{2}{*}{$\begin{array}{c}\text { Doesn't have } \\
\text { a child }\end{array}$} & \\
\hline & Both & One & Neither & Both & One & Neither & & & & \\
\hline $6-9$ & 63 & 11 & 11 & 11 & 7 & 3 & - & - & - & 106 \\
\hline $10-12$ & 59 & 16 & 10 & 10 & 4 & 4 & - & - & - & 103 \\
\hline $13-14$ & 69 & 16 & 12 & 9 & 5 & 5 & 4 & 0 & 0 & 120 \\
\hline $15-17$ & 59 & 22 & 23 & 13 & 12 & 6 & 8 & 3 & 2 & 148 \\
\hline $18-19$ & 17 & 12 & 7 & 18 & 9 & 3 & 15 & 3 & 3 & 87 \\
\hline $20-24$ & 18 & 3 & 10 & 12 & 6 & 18 & 38 & 26 & 4 & 135 \\
\hline Totals & 285 & 80 & 73 & 73 & 43 & 39 & 65 & 32 & 9 & 699 \\
\hline
\end{tabular}

Project SOAR is a six-year (September 2014-September 2020) cooperative agreement funded by the U. S. President's Emergency Plan for AIDS Relief and the U. S. Agency for International Development (Agreement No. AIDOAA-A-14-00060). The contents of this brief are the sole responsibility of Project SOAR and Population Council and do not necessarily reflect the views of PEPFAR, USAID, or the United States Government.

Population Council leads the Project SOAR consortium in collaboration with Avenir Health, Elizabeth Glaser Pediatric AIDS Foundation, the Johns Hopkins University, Palladium, and The University of North Carolina at Chapel Hill.
Project SOAR/Population Council 4301 Connecticut Avenue, NW, Suite 280 Washington, DC 20008

Tel: +1202 2379400

e-mail: ProjectSOAR@popcouncil.org projsoar.org

@P)Pulation Council, March 2019 